\title{
Psychometric properties of the Chinese version of the Self-Efficacy for Appropriate Medication Use Scale in patients with stroke
}

This article was published in the following Dove Press journal:

Patient Preference and Adherence

14 March 2016

Number of times this article has been viewed

\author{
Xiao-fang Dong' \\ Yan-jin Liu ${ }^{2}$ \\ Ai-xia Wang' \\ Pei-hua Lv'
}

'Neurology Department, ${ }^{2}$ Nursing Department, The First Affiliated Hospital of Zhengzhou University, Zhengzhou, People's Republic of China
Correspondence: Yan-jin Liu Nursing Department, The First Affiliated Hospital of Zhengzhou University, I Jianshe Road, Zhengzhou, Henan Province, 450052, People's Republic of China

Tel +86 I35 23548732

Fax $+8637|669| 3035$

Email luomeiruxuel39@sina.com
Background: It has been reported that stroke has a higher incidence and mortality rate in the People's Republic of China compared to the global average. These conditions can be managed by proper medication use, but ensuring medication adherence is challenging.

Objective: To translate the Self-Efficacy for Appropriate Medication Use Scale into Chinese and test its validity and reliability in patients with stroke.

Methods: Instrument performances were measured from January 15, 2015 to April 28, 2015 on a convenience sample of 400 patients with stroke recruited at four neurology departments of the First Affiliated Hospital of Zhengzhou University. Questionnaires included the Chinese versions of the Self-Efficacy for Appropriate Medication Use Scale (C-SEAMS) and the General Self-Efficacy Scale (C-GSE). Construct validity, convergent validity, internal consistency, and test-retest reliability were measured.

Results: Item analysis showed that item-to-total correlations were in the range of 0.362-0.672. Exploratory factor analysis revealed two factors (which accounted for $60.862 \%$ of total variance), with factor loading ranging from 0.534 to 0.756 . Confirmatory factor analysis was performed to support the results, with an acceptable fit $\left(\chi^{2}=73.716 ; d f=64 ; P<0.01\right.$; goodness-of-fit index $=0.902$; adjusted goodness-of-fit index $=0.897$; comparative fit index $=0.865$; root-meansquare error of approximation $=0.058$ ). The convergent validity of the C-SEAMS correlated well with the validated measure of the C-GSE in measuring self-efficacy $(r=0.531, P<0.01)$. Good internal consistency (Cronbach's alpha ranged from 0.826 to 0.915 ) and test-retest reliability (Pearson's correlation coefficient $r=0.642, P<0.01$ ) were found.

Conclusion: The C-SEAMS is a brief and psychometrically sound measure for evaluating self-efficacy for medication adherence in the Chinese population with stroke.

Keywords: psychometric testing, self-efficacy, medication management, stroke, survey designs

\section{Introduction}

It has been reported that stroke has a higher incidence and mortality rate in the People's Republic of China compared to the global average, which is a different pattern from that observed in the Western countries. ${ }^{1}$ Stroke is ranked as the third highest cause of mortality in urban and the first highest in the rural People's Republic of China. ${ }^{2,3}$ For example, the 5-year prevalence of recurrent stroke is 30\%-43\%. Each year, 795,000 people experience a new or recurrent stroke. Approximately 610,000 of these are first attacks, and 185,000 are recurrent. ${ }^{5}$ This risk can be appreciably reduced by preventive treatment aimed at lowering blood pressure and reducing blood cholesterol along with antiplatelet and/or anticoagulation treatment. ${ }^{6}$ All of these can be achieved by 
following relatively straightforward medication regimes, but the success of such treatments is determined to a large degree by medication adherence.

Despite the beneficial effects of medication adherence, it is estimated that medication adherence in stroke survivors is generally poor, ${ }^{7}$ not to mention the fact that cognitive impairment is a common consequence in stroke survivors. ${ }^{8}$ For example, in a study of 3,571 patients with stroke who had been discharged from the hospital, approximately one-third of patients had suboptimal adherence to antihypertensive medications in the year following their stroke. ${ }^{9}$ Psychological aspects have been shown to be related to low medication adherence. One of the psychological constructs that is believed to be an important predictor of medication adherence is "self-efficacy". Self-efficacy, the key construct of Social Cognitive Theory, refers to an individual's judgment of his/her confidence to carry out a specific task in order to produce a desired outcome. ${ }^{10}$ In patients with chronic diseases, positive self-efficacy consistently predicts the adoption of and adherence to a variety of health-related behaviors, including medication adherence, ${ }^{11}$ self-care behavior, and quality of life. ${ }^{12,13}$

Nevertheless, despite evidence documenting the importance of self-efficacy in influencing health behaviors such as medication adherence and the development of several instruments for measuring medication self-efficacy, ${ }^{14,15}$ there is no gold-standard scale for measuring medication self-efficacy. ${ }^{16}$ The Self-Efficacy for Appropriate Medication Use Scale (SEAMS) is brief, quick to administer, and can capture useful data on medication adherence self-efficacy. ${ }^{17}$ Even though the items in this scale are fairly general and particularly well fit for patients with chronic diseases, further assessment of the psychometric properties of the SEAMS in the Chinese population is desirable in order to enhance empirical and clinical use. Therefore, the purpose of the current study was to assess the psychometric properties of the Chinese version of the SEAMS (C-SEAMS) in a sample of patients with stroke.

\section{Materials}

\section{Participants}

This methodological study was conducted at four neurology departments of the First Affiliated Hospital of Zhengzhou University from January 15, 2015 to April 28, 2015. A total of 400 participants were recruited to complete several questionnaires on the day of discharge after stable vital signs. Participants met the following inclusion criteria: they 1) had a diagnosis of stroke, 2) were 18 years or older, 3 ) were taking at least one medication to prevent stroke recurrent after discharge, and 4) formally agreed to participate. Patients with serious psychiatric illness were excluded.

\section{Instruments}

The SEAMS is a 13-item, self-administered instrument developed by Risser et al. ${ }^{17}$ The SEAMS, originally a 21-item scale, is reduced to 13 items after psychometric testing, and so the item number of the SEAMS is discontinuous, including items from 3 to 13 , items 15 and 16 . We changed the order of items 15 and 16 to items 1 and 2, respectively, for the sake of convenience. Patients are asked to indicate, under a number of different circumstances, their level of confidence in taking medications correctly ( $1=$ not confident, $2=$ somewhat confident, and $3=$ very confident). Scores for the 13-item scale range from 13 to 39 . Higher scores indicate higher levels of self-efficacy for medication adherence.

The Chinese version of the General Self-Efficacy Scale (C-GSE) is a ten-item scale measuring a broad and stable sense of personal competence to deal efficiently with a variety of stressful situations. ${ }^{18}$ The C-GSE measures the strength dimension of self-efficacy on a four-point Likert scale. Scores are summed to give a total range from 10 to 40; higher scores represent greater self-efficacy. The C-GSE has shown high internal consistency in a Chinese population (Cronbach's alpha=0.96). ${ }^{19}$

\section{Methods}

\section{Translation and adaptation of the scale}

After Xiao-fang Dong received permission from Risser for the adaptation and use of the SEAMS, it was translated according to international guidelines ${ }^{20,21}$ as follows:

1. Translation and back-translation: The English version of the SEAMS was independently translated into Chinese by the principal researcher and one bilingual pharmacist, who is fluent in both Chinese and English. The two versions were reviewed for inconsistencies. Minor revisions were needed for some words and differences were resolved by discussion until agreement was achieved. Blind back-translation into English was done by two researchers in the nursing fields as the procedure of translation.

2. Content validity (reviewed by six experts): Experts were independently rated for the relevancy and repetition of the content in each item of the original SEAMS in the Chinese culture using a content validity index (CVI) with a fourpoint rating scale. Based on the experts' assessment, the CVI of the SEAMS reached 0.92, meaning appropriate and valid content. 
3. Pilot study: Five Chinese stroke survivors were interviewed to assess whether the C-SEAMS was acceptable and understandable to them.

\section{Data collection}

Participants were approached by the researchers with an information sheet; after written informed consent was obtained, the questionnaires were issued to the participants. The questionnaires were completed principally by the participants themselves, and assistance was given if the participants showed obvious fatigue or had difficulties in writing down their answers by themselves. No direction was provided to prevent response bias. Questionnaires were checked for completeness on return. In addition, 50 stroke patients were selected from this sample and they agreed to take a test-retest reliability analysis. Therefore, 10 days later, the C-SEAMS was administered to these 50 participants on checkup days.

\section{Statistical analysis}

AMOS 20.0 (IBM Corporation, Armonk, NY, USA) was used for confirmatory factor analysis (CFA); all other analyses were performed using SPSS 17.0 (SPSS Inc., Chicago, IL, USA). Mean values and standard deviations (SDs), frequencies, and percentages were used to describe the sample.

\section{Item analysis}

Item analysis enabled researchers to decide which items should be retained and which ones should be omitted. The following criteria were used to identify poorly functioning items: 1 ) a correlation of $<0.30$ between an item and the total scale score (item-total correlation [ITC]) and 2) no decrease in $\alpha$ if the item is deleted. ${ }^{22}$

\section{Construct validity}

Construct validity was tested using exploratory factor analysis (EFA) and verified by CFA. Items with a loading of 0.40 or greater were considered to adequately measure a factor; items that loaded 0.40 or greater onto more than one factor were individually considered and grouped according to interpretability rather than the highest loading. Chi-square/degree-offreedom ratio $\left(\chi^{2} / d f\right)$, root-mean-square error of approximation (RMSEA), goodness-of-fit index (GFI), adjusted goodness-offit index (AGFI), and comparative fit index (CFI) were used to determine the overall data-model fitness.

\section{Convergent validity}

Convergent validity was indicated when two measures thought to reflect the same underlying phenomenon yield similar results or correlate strongly. ${ }^{23}$ Pearson's correlation coefficients were calculated between C-SEAMS and C-GSE scores to determine convergent validity. Participants who reported better C-SEAMS scores were expected to report better C-GSE scores.

\section{Internal consistency}

Internal consistency of the C-SEAMS was determined by computing Cronbach's alpha. Cronbach's alpha described the interrelatedness among the items of a scale to determine the extent to which the items measure the same construct. A Cronbach's alpha of 0.70 or greater was generally accepted to reflect good internal consistency. ${ }^{24}$

\section{Test-retest reliability}

Another approach used in this study to assess the reliability of the scale was to determine the stability of responses over time. Test-retest reliability was examined by computing a Pearson's correlation coefficient between the baseline and the 10-day follow-up C-SEAMS scores of 50 patients. Pearson's correlation coefficient can range from -1 (perfect disagreement) to +1 (perfect agreement), with values less than or equal to 0.40 being considered slight to fair agreement, 0.41 to 0.60 as moderate agreement, and values greater than 0.60 as substantial agreement. ${ }^{25}$

\section{Ethical considerations}

Approval was obtained from the The First Affiliated Hospital of Zhengzhou University's ethics committee. The researchers guaranteed patients that their identities and answers would be kept confidential and they had the freedom to withdraw from the study.

\section{Results}

\section{Sample characteristics}

In the study, 400 participants were recruited to participate. Complete data were available from 374 respondents (response rate: $93.50 \%$ ). Of the 374 Chinese stroke patients, most were male $(65.24 \%)$, married $(86.10 \%)$, and had received elementary or junior high school education $(57.48 \%)$. Their ages ranged from 20 to 87 years (mean $=57.29 ; \mathrm{SD}=11.02$ ). The characteristics of the study participants are shown in Table 1.

\section{Item analysis}

Descriptive statistics of the C-SEAMS scores are presented in Table 2. Mean item scores ranged from 1.55 to 2.34. The corrected ITCs showed moderate-to-strong correlations of all items to the total scale except for item 12, ranging from 0.362 to 0.672 . Cronbach's alpha would not have increased with the deletion of any items in the scale (Table 2). 
Table I Sociodemographic characteristics of the sample $(n=374)$

\begin{tabular}{|c|c|c|}
\hline Descriptive characteristics & Frequency & Percentage \\
\hline \multicolumn{3}{|l|}{ Age, years } \\
\hline \multicolumn{3}{|l|}{$57.29 \pm 11.02$} \\
\hline \multicolumn{3}{|l|}{ Sex } \\
\hline Male & 244 & 65.24 \\
\hline Female & 130 & 34.76 \\
\hline \multicolumn{3}{|l|}{ Marital status } \\
\hline Married & 322 & 86.10 \\
\hline Divorced & 37 & 9.89 \\
\hline Widowed & 15 & 4.01 \\
\hline \multicolumn{3}{|l|}{ Education } \\
\hline Elementary or junior & 215 & 57.48 \\
\hline \multicolumn{3}{|l|}{ high school } \\
\hline Senior high school & 96 & 25.67 \\
\hline College or more & 63 & 16.85 \\
\hline \multicolumn{3}{|l|}{ Employment status } \\
\hline Employed & 185 & 49.47 \\
\hline Retired & 142 & 37.96 \\
\hline Unemployed & 47 & 12.57 \\
\hline \multicolumn{3}{|l|}{ Income } \\
\hline Unknown & 55 & $|4.7|$ \\
\hline$<¥ 20,000 /$ year & 125 & 33.42 \\
\hline$>¥ 20,000 /$ year & 194 & 51.87 \\
\hline \multicolumn{3}{|l|}{ Number of comorbid conditions } \\
\hline Unknown & 12 & 3.21 \\
\hline 0 & 57 & 15.24 \\
\hline $\mathrm{I}-2$ & 156 & 41.71 \\
\hline $3-4$ & 104 & 27.81 \\
\hline$\geq 5$ & 45 & 12.03 \\
\hline
\end{tabular}

Note: Data are presented as mean \pm SD and number (percentage).

Abbreviation: SD, standard deviation.

\section{EFA and CFA}

Prior to conducting the factor analysis, the Kaiser-MeyerOlkin (KMO) measure of sampling adequacy was used to determine whether the partial correlations among variables were small, and Bartlett's test of sphericity was used to determine whether the correlation matrix was an identity matrix, which would indicate that the factor model was inappropriate. ${ }^{26}$ The KMO measure was 0.828 , greater than the minimal acceptable level of 0.50, and Bartlett's test was also acceptable with $P<0.01\left(\chi^{2}=2,055.683\right)$, demonstrating the appropriateness of the sample and correlation matrix (pattern) for factor analysis. ${ }^{27}$

The EFA demonstrated two components with eigenvalues equal to or greater than 1 . The scree plot also showed there were two eigenvalues before the breaking point, and thus, a two-factor solution was retained. These two factors accounted for $60.862 \%$ of the total variance (Table 3 ). Item 7 (When they cause some side effects?) was loaded onto factors 1 (loading: 0.534) and 2 (loading: 0.488), and the item was retained in factor 2 because of the interpretability of the factor and the substantial difference between the two factor loadings (Table 3).

The two-factor measurement model was tested using CFA to confirm the construct validity, which did provide an acceptable fit $\left(\chi^{2}=73.716 ; d f=64 ; P<0.001\right.$; RMSEA $=0.058$; GFI $=0.902$; $\mathrm{AGFI}=0.897$; $\mathrm{CFI}=0.865$ ). All factor loadings were statistically significant in the twofactor model, and all standardized factor loadings were greater than 0.4 ranging from 0.534 to 0.756 (Table 3 ). The two-factor model was therefore selected and used for subsequent analyses.

\section{Convergent validity}

There was a significant positive correlation between C-SEAMS and C-GSE scores $(r=0.531, P<0.01)$, suggesting that the C-SEAMS had acceptable convergent validity.

Table 2 Item analysis of the C-SEAMS $(n=374)$

\begin{tabular}{|c|c|c|c|c|}
\hline Number & Item & Mean \pm SD & ITC & $\begin{array}{l}\text { Cronbach's alpha } \\
\text { (if item deleted) }\end{array}$ \\
\hline I & $\begin{array}{l}\text { When you get a refill of your old medicines and some of the pills } \\
\text { look different than usual? }\end{array}$ & $1.69 \pm 0.69$ & 0.512 & 0.856 \\
\hline 2 & When a doctor changes your medicines? & $1.88 \pm 0.74$ & 0.600 & 0.851 \\
\hline 3 & When you take several different medicines each day? & $2.34 \pm 0.61$ & 0.534 & 0.855 \\
\hline 4 & When you take medicines more than once a day? & $2.01 \pm 0.71$ & 0.493 & 0.857 \\
\hline 5 & When you are away from home? & $2.11 \pm 0.65$ & 0.652 & 0.848 \\
\hline 6 & When you have a busy day planned? & $2.11 \pm 0.64$ & 0.546 & 0.854 \\
\hline 7 & When they cause some side effects? & $2.04 \pm 0.69$ & 0.488 & 0.857 \\
\hline 8 & When no one reminds you to take the medicine? & $2.07 \pm 0.69$ & 0.672 & 0.847 \\
\hline 9 & When the schedule to take the medicine is not convenient? & $1.55 \pm 0.66$ & 0.462 & 0.859 \\
\hline 10 & When your normal routine gets messed up? & $1.99 \pm 0.74$ & 0.551 & 0.854 \\
\hline II & When you are not sure how to take the medicine? & $2.04 \pm 0.68$ & 0.561 & 0.853 \\
\hline 12 & When you are not sure what time of the day to take your medicine? & $1.96 \pm 0.71$ & 0.362 & 0.865 \\
\hline 13 & When you are feeling sick (like having a cold or the flu)? & $1.72 \pm 0.68$ & 0.509 & 0.856 \\
\hline
\end{tabular}

Abbreviations: C-SEAMS, Chinese version of the Self-Efficacy for Appropriate Medication Use Scale; ITC, item-total correlation; SD, standard deviation. 
Table 3 Exploratory factor analysis matrix of the C-SEAMS $(n=374)$

\begin{tabular}{lllll}
\hline Number & Item & Component & Communality \\
\cline { 3 - 4 } & & FI & F2 & C \\
\hline 3 & When you take several different medicines each day? & 0.756 & 0.016 & 0.693 \\
4 & When you take medicines more than once a day? & 0.65 I & 0.204 & 0.606 \\
5 & When you are away from home? & 0.628 & 0.290 & 0.791 \\
6 & When you have a busy day planned? & 0.587 & 0.00 I & 0.734 \\
8 & When no one reminds you to take the medicine? & 0.600 & 0.219 & 0.437 \\
9 & When the schedule to take the medicine is not convenient? & 0.607 & 0.163 & 0.477 \\
I0 & When your normal routine gets messed up? & 0.687 & 0.042 & 0.530 \\
I3 & When you are feeling sick (like having a cold or the flu)? & 0.543 & 0.008 & 0.532 \\
I & When you get a refill of your old medicines and some of the pills look different than usual? & 0.22 I & 0.738 & 0.572 \\
2 & When a doctor changes your medicines? & 0.049 & 0.635 & 0.547 \\
7 & When they cause some side effects? & 0.488 & 0.534 & 0.408 \\
II & When you are not sure how to take the medicine? & 0.184 & 0.558 & 0.800 \\
I2 & When you are not sure what time of the day to take your medicine? & 0.098 & 0.635 & 0.785 \\
& Eigenvalue & 6.064 & 1.643 & -
\end{tabular}

Notes: Principal components analysis is the extraction method used. Coefficients greater than 0.40 are retained for that factor.

Abbreviations: FI, common factor I; F2, common factor 2; C-SEAMS, Chinese version of the Self-Efficacy for Appropriate Medication Use Scale.

\section{Internal consistency reliability and test- retest reliability}

Internal consistencies of the C-SEAMS total scale and subscales were determined using Cronbach's alpha. Cronbach's alpha for the C-SEAMS total scale and two subscales were $0.915,0.826$, and 0.864 , respectively, indicating a good estimate of internal consistency reliability. The test-retest reliability of the C-SEAMS showed good reliability at a 10-day interval among 50 stroke patients. The correlation coefficient between pretest and posttest was $0.642(P<0.01)$.

\section{Discussion}

It is crucial to develop a validated measure to assess selfefficacy for medication adherence in patients with chronic diseases such as stroke, especially in the People's Republic of China, where the rate of stroke is high. The results of the study demonstrate the reliability and validity of the C-SEAMS, which will facilitate future use of the C-SEAMS in Chinese patients with stroke.

The results of EFA of the C-SEAMS were a little different from those obtained from the original English version. ${ }^{17}$ In fact, in the development of the English version, EFA in a group of patients with a different literacy level revealed a similar two-factor solution, but with crossover of two items. For low-literacy patients, the two subscales are selfefficacy for taking medications under difficult circumstances (factor 1: items 3, 4, 5, 6, 8, 9, 10, and 13) and self-efficacy for taking medications under uncertain or changing circumstances (factor 2: items 1, 2, 7, 11, and 12). For the English version with higher literacy patients, items 10 and 13 loaded onto factor 2. The authors provided no explanation for the item crossover between different literacy groups, and thus, all 13 items should be used rather than its two potential subscales. In the C-SEAMS, a two-factor solution accounted for $60.862 \%$ of the overall variance, which was sufficient for factor analysis. Items retained in the two factors were the same with the English analysis in the low-literacy population. The reason was that more than half $(57.48 \%)$ of the participants in this study had received elementary or junior high school education, and were considered low-literacy patients both in the People's Republic of China and in English-speaking countries. One of the limitations of the original English version was that there was no CFA examination. So CFA was performed in our study to determine the construct validity. However, the results of CFA supported the two-factor model reported by Risser, ${ }^{17}$ which suggested that medication adherence self-efficacy, as measured by the SEAMS, was a two-dimensional construct. In general, the criteria for goodness-of-fit included $\chi^{2} / d f<3.00$, RMSEA $<0.08$, GFI, AGFI, and CFI $\geq 0.90 .{ }^{28}$ In this study, an acceptable fit $\left(\chi^{2}=73.716 ; d f=64 ; P<0.001 ;\right.$ RMSEA $=0.058$; $\mathrm{GFI}=0.902 ; \mathrm{AGFI}=0.897$; $\mathrm{CFI}=0.865)$ were obtained. Even though some of the results $(\mathrm{AGFI}=0.897, \mathrm{CFI}=0.865) \mathrm{did}$ not achieve 0.90 , it was acceptable. ${ }^{28}$ Future studies using this scale should be carried out to confirm or extend upon these findings.

The C-SEAMS demonstrated good convergent validity. Convergent validity was generated from correlations between two different tools measuring the same trait. ${ }^{29}$ The correlational analysis revealed that the C-SEAMS had excellent convergent validity when assessed against the C-GSE. A moderate association $(r=0.531, P<0.01)$ was observed 
between C-GSE and C-SEAMS scores, demonstrating the convergent validity of the C-SEAMS.

Internal consistency and test-retest reliability were acceptable for all subscales. Cronbach's alpha was used to determine the internal consistency, and Cronbach's alpha for the total scale and two subscales was 0.915, 0.826, and 0.864 , respectively, which was sufficient for assessment at an individual level. ${ }^{30}$ These findings were similar to those of the English version, ${ }^{17}$ where the total Cronbach's alpha was 0.89 . The test-retest reliability results were slightly higher than those of the English version $(r=0.57, P<0.01) .{ }^{17}$ This may be because of differences in the test-retest time. Polit and Beck $^{29}$ recommended a period of 2 weeks to a month between test and retest in nursing research. If the time frame is too short, subjects may remember their response from the initial test, or if some incentives or interventions are given, reliability might be overestimated. In our study, a period of 10 days was chosen considering that stroke patients were asked to return for checkup in 10 days at our hospital. Although no incentives or interventions were given between the two tests, a period of 10 days was shorter than 2 weeks, which may explain why the test-retest reliability in our study was slightly higher than it was for the English version.

\section{Limitations}

Several limitations to the current study are worth noting. First, generalizability of the findings may be restricted because convenience sampling was used when recruiting participants. Further, the sample consisted of less than $40 \%$ female patients. Although the prevalence of stroke is consistently higher in male patients than in female patients in the People's Republic of China, ${ }^{31,32}$ we must exercise caution in generalizing the study findings to the female population. Second, only internal consistency, test-retest reliability, convergent validity, and construct validity were used in this study to confirm reliability and validity. Other measures such as predictive validity should be investigated to further verify the psychometric properties of the scale. In addition, the study did not conduct EFA in populations with other chronic diseases such as heart diseases, diabetes mellitus, and hypertension. Third, the translation of the scale in this study was carried out by the research team, which was less reliable compared to one that could be produced by professional bilingual translators using multiple techniques such as focus groups and think-aloud interviews with members of the target population.

\section{Conclusion}

The reliability and validity information presented support the use of 13-item C-SEAMS as a measure of self-efficacy for medication adherence in the Chinese population with stroke. In addition, the 13-item C-SEAMS is relatively short and easy to administer. This instrument will facilitate the design of more cross-cultural studies, and the use of C-SEAMS may encourage nurses and physicians to better understand and take a psychosocial approach to medication adherence in patients with stroke.

\section{Acknowledgments}

Thanks to Jessica Risser (Emory University School of Medicine, Atlanta, GA, USA) for the authorization of our translation of the SEAMS into Chinese. We wish to thank Huan-huan Gao, Jiao-jiao Zhu, Min Wang, and Qiu-lu Xu from other neurology departments of the affiliated hospitals of Zhengzhou University, for their assistance in the recruitment of participants. We also acknowledge all the experts and participants involved in this study for their generous information and support. Lastly, we would like to thank Editage for English language editing.

\section{Disclosure}

The authors report no conflicts of interest in this work.

\section{References}

1. Zhao JJ, He GQ, Gong SY, He L. Status and costs of primary prevention for ischemic stroke in China. J Clin Neurosci. 2013;20(10): $1427-1432$.

2. Wu X, Zou S, Zhu B, Shi J. The hospital costs of stroke patients in Chinese island populations: an 11-year tendency analysis. $J$ Stroke Cerebrovasc Dis. 2015;24(5):988-992.

3. Sun XG, Wang T, Zhang N, Yang QD, Liu YH. Incidence and survival of lacunar infarction in a southern Chinese population: a 7-year prospective study. Brain Inj. 2015;29(6):739-744.

4. Ji R, Liu G, Shen H, et al. Persistence of secondary prevention medications after acute ischemic stroke or transient ischemic attack in Chinese population: data from China National Stroke Registry. Neurol Res. 2013;35(1):29-36.

5. Roger VL, Go AS, Lloyd-Jones DM, et al. Heart disease and stroke statistics - 2011 update: a report from the American Heart Association. Circulation. 2011;123(4):e18-e209.

6. Sudlow C. Preventing further vascular events after a stroke or transient ischaemic attack: an update on medical management. Pract Neurol. 2008;8(3):141-157.

7. Bushnell CD, Zimmer LO, Pan W, et al. Persistence with stroke prevention medications 3 months after hospitalization. Arch Neurol. 2010;67(12):1456-1463

8. O'Carroll R, Whittaker J, Hamilton B, Johnston M, Sudlow C, Dennis M. Predictors of adherence to secondary preventive medication in stroke patients. Ann Behav Med. 2011;41(3):383-390.

9. Khan NA, Yun L, Humphries K, Kapral M. Antihypertensive drug use and adherence after stroke: are there sex differences? Stroke. 2010;41(7):1445-1449. 
10. Bandura A. Self-efficacy: toward a unifying theory of behavioral change. Psychol Rev. 1977;84(2):191-215.

11. Chen WT, Wantland D, Reid P, et al. Engagement with health care providers affects self-efficacy, self-esteem, medication adherence and quality of life in people living with HIV. J AIDS Clin Res. 2013; 4(11):256.

12. Walker RJ, Smalls BL, Hernandez-Tejada MA, Campbell JA, Egede LE. Effect of diabetes self-efficacy on glycemic control, medication adherence, self-care behaviors, and quality of life in a predominantly lowincome, minority population. Ethn Dis. 2014;24(3):349-355.

13. Abraham KM, Miller CJ, Birgenheir DG, Lai Z, Kilbourne AM. Self-efficacy and quality of life among people with bipolar disorder. J Nerv Ment Dis. 2014;202(8):583-588.

14. Fernandez S, Chaplin W, Schoenthaler AM, Ogedegbe G. Revision and validation of the medication adherence self-efficacy scale (MASES) in hypertensive African Americans. J Behav Med. 2008;31(6):453-462.

15. Kalichman SC, Cain D, Fuhrel A, Eaton L, Di Fonzo K, Ertl T. Assessing medication adherence self-efficacy among low-literacy patients: development of a pictographic visual analogue scale. Health Educ Res. 2005;20(1):24-35.

16. Lavsa SM, Holzworth A, Ansani NT. Selection of a validated scale for measuring medication adherence. J Am Pharm Assoc (2003). 2011;51(1) 90-94.

17. Risser J, Jacobson TA, Kripalani S. Development and psychometric evaluation of the Self-Efficacy for Appropriate Medication Use Scale (SEAMS) in low-literacy patients with chronic disease. $J$ Nurs Meas. 2007;15(3):203-219.

18. Cheung SK, Sun SY. Assessment of optimistic self-beliefs: further validation of the Chinese version of the General Self-Efficacy Scale. Psychol Rep. 1999;85(3 Pt 2):1221-1224.

19. Leung DY, Leung AY. Factor structure and gender invariance of the Chinese General Self-Efficacy Scale among soon-to-be-aged adults. J Adv Nurs. 2011;67(6):1383-1392.
20. Wild D, Grove A, Martin M, et al. Principles of good practice for the translation and cultural adaptation process for patient-reported outcomes (PRO) measures: report of the ISPOR Task Force for Translation and Cultural Adaptation. Value Health. 2005;8(2):94-104.

21. Guillemin F, Bombardier C, Beaton D. Cross-cultural adaptation of health-related quality of life measures: literature review and proposed guidelines. J Clin Epidemiol. 1993;46(12):1417-1432.

22. Ferketich S. Focus on psychometrics. Aspects of item analysis. Res Nurs Health. 1991;14(2):165-168.

23. Portney LG, Watkins MP. Foundations of Clinical Research. Applications to Practice. 3rd ed. Upper Saddle River, NJ: Pearson Education, Inc.; 2009.

24. Nunnally JC, Bernstein RL. Psychometric Theory. 3rd ed. New York: McGraw-Hill; 1994.

25. Kramer MS, Feinstein AR. Clinical biostatistics. LIV. The biostatistics of concordance. Clin Pharmacol Ther. 1981;29(1):111-123.

26. Norusis M. SPSS 15.0 Guide to Data Analysis. Upper Saddle River, NJ: Prentice Hall; 2007.

27. George D, Mallery P. SPSS for Windows Step by Step: A Simple Guide and Reference. 6th ed. Boston, MA: Allyn \& Bacon; 2006.

28. Byrne BM. Structural Equation Modeling with LISREL, PRELIS and SIMPLIS: Basic Concepts, Applications, and Programming. Mahwah, NJ: Lawrence Erlbaum Associates; 1998.

29. Polit DF, Beck CT. Nursing Research: Principles and Methods. Philadelphia, PA: Lippincott Williams \& Wilkins; 2004.

30. Rosner B. Fundamentals of Biostatistics. 7th ed. Toronto, ON: Cengage Learning Inc.; 2010.

31. Tsai CF, Anderson N, Thomas B, Sudlow CL. Risk factors for ischemic stroke and its subtypes in Chinese vs. Caucasians: systematic review and meta-analysis. Int $J$ Stroke. 2015;10(4):485-493.

32. Wang J, An Z, Li B, et al. Increasing stroke incidence and prevalence of risk factors in a low-income Chinese population. Neurology. 2015; 84(4):374-381.
Patient Preference and Adherence

\section{Publish your work in this journal}

Patient Preference and Adherence is an international, peer-reviewed, open access journal that focuses on the growing importance of patient preference and adherence throughout the therapeutic continuum. Patient satisfaction, acceptability, quality of life, compliance, persistence and their role in developing new therapeutic modalities and compounds to optimize

\section{Dovepress}

clinical outcomes for existing disease states are major areas of interest for the journal. This journal has been accepted for indexing on PubMed Central. The manuscript management system is completely online and includes a very quick and fair peer-review system, which is all easy to use. Visit http://www. dovepress.com/testimonials.php to read real quotes from published authors. 